\title{
PEMANFAATAN SOFTWARE MATLAB DALAM PEMBELAJARAN METODE NUMERIK POKOK BAHASAN SISTEM PERSAMAAN LINEAR SIMULTAN
}

\author{
Any Muanalifah \\ Dosen Jurusan Tadris Matematika FITK IAIN Walisongo
}

\begin{abstract}
Abstrak
Persoalan yang melibatkan model matematika banyak muncul dalam berbagai disiplin ilmu pengetahuan, seperti dalam bidang fisika, kimia, ekonomi, atau pada persoalan rekayasa. Seringkali model matematika tersebut muncul dalam bentuk yang rumit yang terkadang tidak dapat diselesaikan dengan rumus-rumus aljabar yang sudah baku. Permasalahan ini dapat diselesaikan dengan Menggunakan metode Numerik.

Dalam pembelajaran metode Numerik khususnya pada pokok bahasan Sistem Persamaan Linear Simultan diperlukan perhitungan iterasi dengan menggunakan Komputer. Software yang digunakan untuk perhitungan Numerik salah satunya adalah MATLAB. Dengan pemanfaatan software ini ternyata sangat membantu pemebelajaran metode numerik
\end{abstract}

Kata Kunci : Matlab, Metode Numerik, Sistem Persamaan Linear Simultan 


\section{PENDAHULUAN}

Tidak semua permasalahan matematika dapat diselesaikan dengan mudah secara analitik. Bahkan dalam prinsip matematika, dalam memandang permasalahan yang terlebih dahulu diperhatikan apakah permasalahan tersebut mempunyai penyelesaian atau tidak. Hal ini menjelaskan bahwa tidak semua permasalahan matematika dapat diselesaikan dengan menggunakan perhitungan biasa.[1]

Sebagai contoh :

$$
L=\int_{0}^{1} \frac{\sin (x)}{x} d x
$$

Integral diatas terlihat tidak terlalu panjang, tetapi untuk menyelesaikan integral tersebut bukan permasalahan yang mudah bahkan dapat dikatakan tidak mungkin. Tetapi bukan berarti integral tersebut tidak mempunyai penyelesaian, hanya saja menyelesaikan integral semacam itu sangat sulit dan kalaupun bisa memerlukan pengetahuan matematis yang tinggi dan waktu yang cukup lama. Padahal integral diatas adalah bentuk integral yang banyak digunakan dalam bidang teknik.

Dengan dasar inilah dapat dikatakan bahwa diperlukan suatu metode tertentu yang digunakan untuk menghitung integral tersebut. Meskipun metode tersebut tidak dapat menghasilkan nilai yang exact (tepat), setidak-tidak sudah mendekati nilai yang diharapkan.

Selain adanya persoalan diatas, seiring dengan perkembangan komputer sebagai alat bantu dalam menyelesaikan persoalan, maka pemakaian metode analitik terkadang sulit diterjemahkan ke dalam algoritma yang dapat dimengerti oleh komputer. Sehingga metode numerik yang memang berangkat dari pemakaian alat bantu hitung merupakan alternatif yang baik dalam menyelesaikan persoalan-persoalan perhitungan yang rumit. Telah banyak yang menawarkan program-program numerik sebagai alat bantu perhitungan. 
Dalam penerapan matematis untuk menyelesaikan persoalan-persoalan perhitungan dan analisis, ada beberapa keadaan dan metode yang digunakan untuk menghasilkan penyelesaian yang baik adalah:

1. Bila persoalan merupakan persoalan sederhana ata ada teorema analisa matematika yang dapat digunakan untuk menyelesaikan persoalan tersebut, maka penyelesaian matematis (metode analitik) adalah penyelesaian exact yang harus digunakan. Penyelesaian ini menjadi acuan bagi pemakaian metode pendekatan.

2. Bila persoalan sudah sangat sulit atau tidak mungkin diselesaikan secara matematis (analitik) karena tidak ada teorema analisis matematik yang dapat digunakan, maka dapat digunakan metode numerik

3. Bila persoalan sudah merupakan persoalan yang mempunyai kompleksitas tinggi, sehingga metode numerik pun tidak dapat menyajikan penyelesaian dengan baik, maka dapat digunakan metode-metode simulasi.

Pendekatan yang digunakan dalam metode numerik merupakan pendekatan analisis matematis. Sehingga dasar pemikirannya tidak keluar jauh dari dasar pemikiran analitis, hanya saja pemakaian grafis dan teknik perhitungan yang mudah merupakan pertimbangan dalam pemakaian metode numerik. Mengingat bahwa algoritma yang dikembangkan dalam metode numerik adalah algoritma pendekatan maka dalam algoritma tersebut akan muncul iterasi yaitu pengulangan proses perhitungan. Dengan kata lain perhitungan dalam metode numerik adalah perhitungan yang dilakukan secara berulang-ulang untuk terus-menerus diperoleh hasil yang mendekati nilai penyelesaian exact.

Salah satu pokok bahasan yang dikerjakan secara numerik adalah sistem persamaan linear simultan, karena sistem persamaan linear memerlukan ketelitian dan waktu yang lama jika dihitung menggunakan metode analitik. Metode iterasi GaussJordan adalah salah satu metode numerik yang digunakan un- 
tuk mencari penyelesaian sistem persamaan linear simultan. Dalam perhitungannya metode ini memerlukan bantuan komputer karena iterasi yang diperlukan sangat banyak sehingga tidak mungkin jika dihitung secara manual.

Software yang digunakan di sini adalah MATLAB yang merupakan salah satu software matematika yang paling sering digunakan. MATLAB (Matrix Laboratory) adalah bahasa komputasi teknis tingkat tinggi dan lingkungan interaktif untuk pengembangan algoritma, visualisasi data, analisis data dan komputasi numerik. [1]

\section{PEMBAHASAN}

\section{SISTEM PERSAMAAN LINEAR SIMULTAN}

Sistem persamaan linier merupakan salah satu model dan masalah matematika yang banyak dijumpai dalam berbagai disiplin ilmu, termasuk fisika, biologi , teknik dll. Sistem persamaan linier muncul secara langsung dari masalah nyata, dan merupakan bagian dari proses penyelesaian masalah-masalah lain, misalnya penyelesaian sistem persamaan non linier simultan.[4]

Suatu sistem persamaan linier adalah sistem persamaan yang terdiri dari sejumlah persamaan (berhingga) dan sejumlah variabel (berhingga). Mencari solusi suatu sistem persamaan linier adalah mencari nilai-nilai variable-variabel tersebut, sehingga memenuhi semua sistem persamaan tersebut. Terdapat dua metode untuk mencari solusi sistem persamaan linier yaitu [8] :

1. Metode langsung, yang terdiri dari metode eliminasi Gauss, metode eliminasi Gauss-Jordan, metode matriks invers dan metode dekomposisi LU.

2. Metode tak langsung yaitu metode iterasi, yang terdiri dari metode iterasi Jacobi dan metode iterasi Gauss-Seidel, dimana dalam metode iterasi ini harus diberikan solusi awal ( merupakan tebakan ).

Bentuk umum sistem persamaan linier (SPL) yang terdiri dari $n$ variabel dan $n$ persamaan adalah sebagai berikut, 


$$
\begin{aligned}
& a_{11} x_{1}+a_{12} x_{2}+a_{13} x_{3}+a_{14} x_{4}+\ldots+a_{1 n} x_{n}=b_{1} \\
& a_{21} x_{1}+a_{22} x_{2}+a_{23} x_{3}+a_{24} x_{4}+\ldots+a_{2 n} x_{n}=b_{2} \\
& a_{31} x_{1}+a_{32} x_{2}+a_{33} x_{3}+a_{34} x_{4}+\ldots+a_{3 n} x_{n}=b_{3}
\end{aligned}
$$

Kuantitas-kuantitas $a_{i j}$ (untuk $\left.i, j=1,2,3, \ldots, n\right)$ disebut koefisien. Nilai koefisien-koefisien $a_{i j}$ dan $b_{i}$ pada setiap persamaan diketahui. Kuantitas-kuantitas $x_{i}$ disebut variable, yang nilainya belum diketahui dan akan dicari.

Apabila semua nilai $b_{i}=0$ untuk $i=1,2,3, \ldots, n$, maka SPL (6.1) disebut sistem homogen. Jika terdapat $b_{k} \neq 0$ untuk semua $1 \leq k \leq n$, maka SPL (6.1) disebut sistem tak homogen. Sistem homogen memegang peranan penting untuk menentukan apakah SPL (6.1) mempunyai solusi atau tidak. Beberapa kemungkinan yang terdapat pada SPL seperti persamaan 6.1, yaitu,

1. SPL mempunyai tepat sebuah solusi $x$ / solusi unik (Gambar 1)

2. SPL mempunyai banyak solusi $x$ (Gambar 2)

3. SPL tidak mempunyai solusi (Gambar 3)

Berdasarkan interpretasi geometri ketiga kemungkinan tersebut dapat digambarkan sebagai berikut:
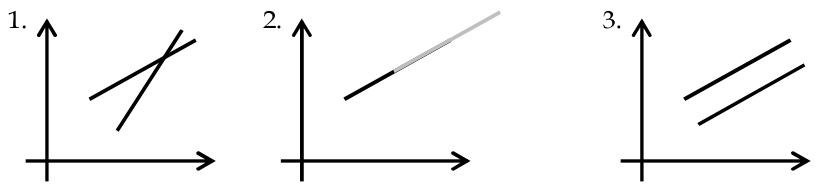

Metode ini merupakan suatu teknik untuk mencari solusi SPL yang berukuran $\mathrm{n} \times \mathrm{n}, \mathrm{AX}=\mathrm{B}$ secara iteratif. Proses penyelesaian dimulai dengan suatu solusi awal, $x_{i}^{(0)}$ (tebakan kita), kemudian dilakukan iterasi berikutnya untuk mendapatkan hasil hampiran sesuai dengan ketentuan kriteria berhenti. Teknik solusi iteratif ini lebih efisien digunakan untuk SPL yang berukuran besar. Metode iterasi Jacobi ini dinyatakan oleh rumus 
sebagai berikut, $x_{i}^{(k)}=\frac{1}{a_{i i}}\left(b_{i}-\sum_{j \neq i} a_{i j} x_{j}^{(k-1)}\right) \operatorname{dgn} i=1,2,3, \ldots, n$ dan $k=1,2,3 \ldots$. Sebagai kriteria berhenti iterasi adalah $\left|\frac{x_{i}^{(k+1)}-x_{i}^{(k)}}{x_{i}^{(k+1)}}\right|<\varepsilon$, utk semua $i=1,2,3, \ldots, n$. Dan syarat cukup agar iterasinya konvergen adalah matriks A dari SPL dominant secara diagonal:

$$
\left|a_{i i}\right|>\sum_{\substack{j=1 \\ j \neq i}}^{n}\left|a_{i i}\right| \operatorname{dgn} i=1,2,3, \ldots, n
$$

Syarat cukup ini berarti bahwa agar iterasinya konvergen, cukup dipenuhi syarat itu. Jika syarat tersebut terpenuhi, kekonvergenan dijamin, meskipun matriks A dari SPL tidak dominan secara diagonal iterasinya mungkin konvergen. Kekonvergenan juga ditentukan oleh tebakan awal. Tebakan awal yang terlalu jauh dari solusi eksaknya dapat menyebabkan iterasi divergen.

Contoh

Cari solusi SPL ini dengan metode iterasi Jacobi dengan tebakan awal $(0,0,0,0)^{\top}$.

$$
\begin{aligned}
& 10 x_{1}-x_{2}+2 x_{3}+0 x_{4}=6 \\
& -x_{1}+11 x_{2}-x_{3}+3 x_{4}=25 \\
& 2 x_{1}-x_{2}+10 x_{3}-x_{4}=-11 \\
& 0 x_{1}+3 x_{2}-x_{3}+8 x_{4}=15
\end{aligned}
$$

Jawab:

SPL tersebut dapat ditulis sebagai

$$
\begin{aligned}
& \left(\begin{array}{cccc}
10 & -1 & 2 & 0 \\
-1 & 11 & -1 & 3 \\
2 & -1 & 10 & -1 \\
0 & 3 & -1 & 8
\end{array}\right)\left(\begin{array}{l}
x_{1} \\
x_{2} \\
x_{3} \\
x_{4}
\end{array}\right)=\left(\begin{array}{c}
6 \\
25 \\
-11 \\
15
\end{array}\right) \text { dengan } \\
\mathrm{A} & =\left(\begin{array}{cccc}
10 & -1 & 2 & 0 \\
-1 & 11 & -1 & 3 \\
2 & -1 & 10 & -1 \\
0 & 3 & -1 & 8
\end{array}\right), \mathrm{X}=\left(\begin{array}{l}
x_{1} \\
x_{2} \\
x_{3} \\
x_{4}
\end{array}\right) \text { dan } \mathrm{B}=\left(\begin{array}{c}
6 \\
25 \\
-11 \\
15
\end{array}\right)
\end{aligned}
$$

Tampak bahwa matriks A dominan secara diagonal. 
Mula-mula kita nyatakan setiap variabel dalam ketiga variabel yang lain, yaitu sebagai berikut:

$$
\begin{aligned}
& x_{1}=\frac{6+x_{2}-2 x_{3}}{10} \\
& x_{2}=\frac{25+x_{1}+x_{3}-3 x_{4}}{11} \\
& x_{3}=\frac{-11-2 x_{1}+x_{2}+x_{4}}{10} \\
& x_{4}=\frac{15-3 x_{2}+x_{3}}{8}
\end{aligned}
$$

Kemudian kita substitusikan tebakan awal kedalam pers. $7.1 \mathrm{~s} / \mathrm{d}$ 7.4, hasilnya adalah nilai $x$ pada iterasi ke-1, yaitu sebagai berikut:

$$
\begin{aligned}
& x_{1}^{(1)}=\frac{6+0-2 \times 0}{10}=\frac{6}{10}=0,6 \\
& x_{2}^{(1)}=\frac{25+0+0-3 \times 0}{11}=\frac{25}{11}=2,2727 \\
& x_{3}^{(1)}=\frac{-11-2 \times 0+0+0}{10}=\frac{-11}{10}=-1,1 \\
& x_{1}^{(1)}=\frac{15-3 \times 0+0}{8} .=\frac{15}{8}=1,8750
\end{aligned}
$$

\section{Iterasi ke-2}

$$
\begin{aligned}
& x_{1}^{(2)}=\frac{6+x_{2}^{(1)}-2 x_{3}^{(1)}}{10}=1,04727 \\
& x_{2}^{(2)}=\frac{25+x_{1}^{(1)}+x_{3}^{(1)}-3 x_{4}^{(1)}}{11}=1,71591 \\
& x_{3}^{(2)}=\frac{-11-2 x_{1}^{(1)}+x_{2}^{(1)}+x_{4}^{(1)}}{10}=-0,805227 \\
& x_{4}^{(2)}=\frac{15-3 x_{2}^{(1)}+x_{3}^{(1)}}{8}=0,885227
\end{aligned}
$$


Any Muanalifah

\section{Iterasi ke-3}

$$
\begin{aligned}
& x_{1}^{(3)}=\frac{6+x_{2}^{(2)}-2 x_{3}^{(2)}}{10}=0,932636 \\
& x_{2}^{(3)}=\frac{25+x_{1}^{(2)}+x_{3}^{(2)}-3 x_{4}^{(2)}}{11}=2,05331 \\
& x_{3}^{(3)}=\frac{-11-2 x_{1}^{(2)}+x_{2}^{(2)}+x_{4}^{(2)}}{10}=-1,04934 \\
& x_{4}^{(3)}=\frac{15-3 x_{2}^{(2)}+x_{3}^{(2)}}{8}=1,13088
\end{aligned}
$$

\section{Iterasi ke-4}

$$
\begin{aligned}
& x_{1}^{(4)}=\frac{6+x_{2}^{(3)}-2 x_{3}^{(3)}}{10}=1,015200 \\
& x_{2}^{(1)}=\frac{25+x_{1}^{(3)}+x_{3}^{(3)}-3 x_{4}^{(3)}}{11}=1,953700 \\
& x_{3}^{(1)}=\frac{-11-2 x_{1}^{(3)}+x_{2}^{(3)}+x_{4}^{(3)}}{10}=-0,968109 \\
& x_{1}^{(4)}=\frac{15-3 x_{2}^{(3)}+x_{3}^{(3)}}{8}=0,973843
\end{aligned}
$$

\section{Sampai dengan iterasi ke-8}

\section{MATLAB Iterasi Jacobi}

Berikut ini adalah script dalam MATLAB

$$
\begin{aligned}
& \text { function }[\mathrm{X}, \mathrm{g}, \mathrm{H}]=\text { jacobi }(\mathrm{A}, \mathrm{b}, \mathrm{X} 0, \mathrm{~T}, \mathrm{~N}) \\
& \mathrm{H}=\mathrm{X} 0^{\prime} \text {; } \\
& \mathrm{n}=\text { length }(\mathrm{b}) \text {; } \\
& \mathrm{X} 1=\mathrm{X} 0 \text {; } \\
& \text { for } \mathrm{k}=1: \mathrm{N} \text {, } \\
& \text { for } \mathrm{i}=1: \mathrm{n} \text {, } \\
& \mathrm{S}=\mathrm{b}(\mathrm{i})-\mathrm{A}(\mathrm{i},[1: \mathrm{i}-1, \mathrm{i}+1: \mathrm{n}]) * X 0([1: \mathrm{i}-1, \mathrm{i}+1: \mathrm{n}]) \text {; } \\
& \mathrm{X} 1(\mathrm{i})=\mathrm{S} / \mathrm{A}(\mathrm{i}, \mathrm{i}) \text {; } \\
& \text { end } \\
& \mathrm{g}=\operatorname{abs}(\mathrm{X} 1-\mathrm{X} 0) \text {; } \\
& \text { err }=\operatorname{norm}(\mathrm{g}) \text {; } \\
& \text { relerr }=\text { err } /(\text { norm }(X 1)+\text { eps }) \text {; } \\
& \mathrm{X} 0=\mathrm{X} 1 \text {; }
\end{aligned}
$$




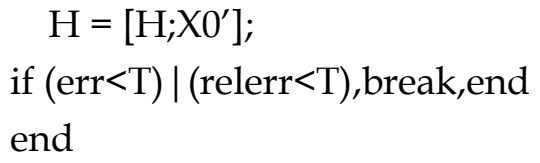

\section{Layar Editor MATLAB 7}

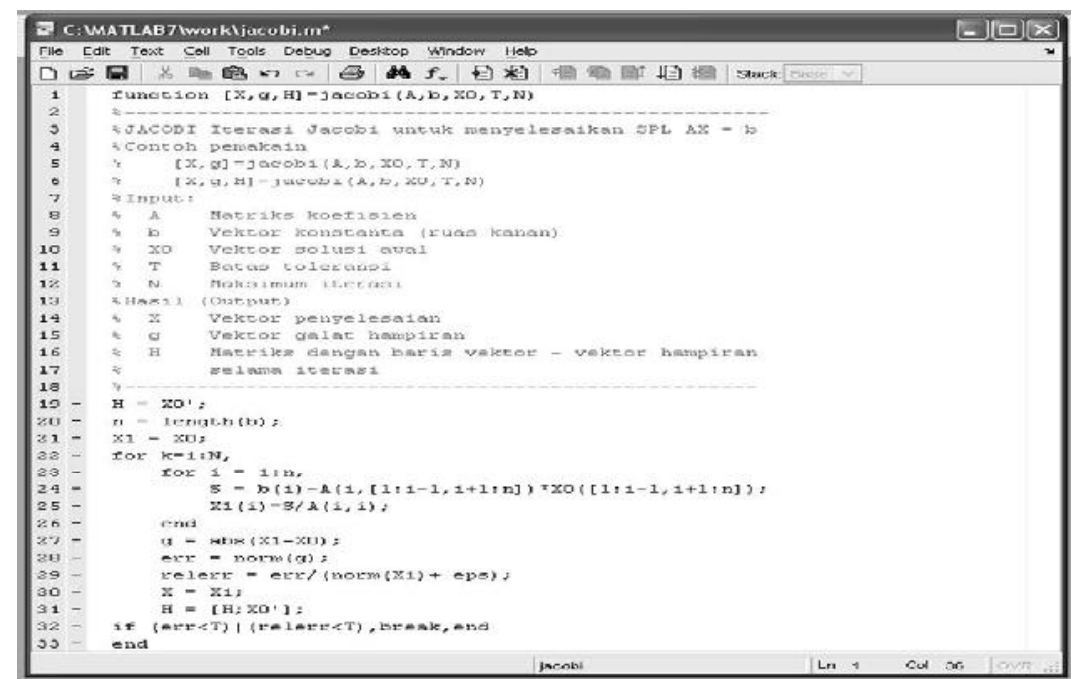

\begin{tabular}{|c|c|c|c|c|}
\hline$r$ & $x_{1}$ & $x_{2}$ & $x_{3}$ & $x_{4}$ \\
\hline 1 & 0,600000 & 2,272730 & $-1,100000$ & 1,875000 \\
\hline 2 & 1,047270 & 1,715910 & $-0,805227$ & 0,885227 \\
\hline 3 & 0,932636 & 2,053310 & $-1,049340$ & 1,130880 \\
\hline 4 & 1,015200 & 1,953700 & $-0,968109$ & 0,973843 \\
\hline 5 & 0,988991 & 2,011410 & $-1,010290$ & 1,021350 \\
\hline 6 & 1,003200 & 1,992240 & $-0,994522$ & 0,994434 \\
\hline 7 & 0,998128 & 2,002310 & $-1,001970$ & 1,003590 \\
\hline 8 & $\mathbf{1 , 0 0 0 6 3 0}$ & $\mathbf{1 , 9 9 8 6 7 0}$ & $-0,999036$ & $\mathbf{0 , 9 9 8 8 8 8}$ \\
\hline
\end{tabular}

Setelah iterasi ke-8, maka hasilnya adalah

$$
\begin{array}{ll}
x_{1}=1,000630 & x_{3}=-0,999036 \\
x_{2}=1,998670 & x_{4}=0,998888
\end{array}
$$


Any Muanalifah

\section{KESIMPULAN}

Penggunaan Software MATLAB dalam pembelajaran metode Numerik pokok bahasan Sistem Persamaan Linear Simultan akan sangat membantu siswa, karena siswa dapat dengan mudah melakukan perhitungan iterasi menggunakan algoritma yang dibuat di MATLAB.

Selain itu penggunaan software MATLAB dapat memotivasi siswa dalam mengikuti perkuliahan Metode Numerik 


\section{DAFTAR PUSTAKA}

Basuki, Achmad. 2005. Metode Numerik dan Algoritma Komputasi. Yogyakarta:ANDI

Buchanan, James I., Numerical Methods and Analysis, McGrawHill International Editions, 1992

Chapra, Steven C dan Canale, Raymond P, Numerical Methods for Engineers with Personal Computer Applications, MacGrawHill Book Company, 1991

[CON92] Conte, Samuel D dan De Boor, Carl, Elementary NumericalAnalysis, An Algorithmic Approach, 3rd Edition, MacGraw-Hills, Inc, 1992.

Dulimarta, Hansye S., Diktat Kuliah Pengolahan Citra Digital, Teknik Informatika ITB, 1996

Gerald, Curtis F dan Wheatley, Pattrick O, Applied Numerical Analysis, 3rd Edition, Addison-Wesley Publishing Company, 1985

Kreyszic, Erwin, Advanced Engineering Mathematics, John Wiley and Sons, 1988

Mathews, Johh. H, Numerical Methods for Mathematics, Science and Engineering, 2nd Edition, Prentice-Hall International, 1993 